\title{
An Exploratory Study Of Language Attitudes Among Second Cycle Students In The New Juaben Municipality Of Ghana
}

\author{
*Ishmael Duah, Solomon Ernest Mensah
}

Koforidua Technical University, Koforidua

*maja233@yahoo.com

\begin{abstract}
This paper is concerned with the relationship between attitude and behaviour in language. Adolescent male and female subjects were recorded and index-scores of their linguistic behaviour compared to their assessment of ingroup members in a verbal-guise attitude experiment, and to their attitudes concerning language usage in a questionnaire. It was hypothesized that male subjects' language would be closer to the vernacular, and that they would also express more positive attitudes towards in-group members than would female subjects. However, no significant correlation between attitude and behaviour was found in the quantitative analysis, but results from the attitude-questionnaire support our hypothesis: male subjects have more vernacular features in their language and also express more genuinely positive attitudes towards the local vernaculars than do female subjects. Finally, methodological and theoretical implications of these results are discussed, emphasizing the importance of using eclectic approaches in future research on attitude-behaviour relations in language.
\end{abstract}

Keywords: Language attitudes; attitude-behaviour relations

\section{Introduction}

Attitudes are learned predispositions, not inherited, and are likely to be relatively stable (Baker, 1988). According to Crystal (1992), language attitudes are the feelings people have about their own language or the languages of others. Attitude to language is an idea that explains linguistic behaviour towards a language. This behaviour may be negative or positive, instrumental or integrative, favourable or unfavourable in language learning and acquisition, choice and use of language in the various domains. As a result, attitude to a language is very important in the survival and development of any language, and also in the chances of success in any language policy involving the language in question. Attitudes are important in determining language growth or decay, restoration or destruction. They can also be instrumental in determining the success or otherwise of a language policy. (Ghana as example, the many failed language policies---negative attitudes of teachers, students and parents towards native languages). Language attitudes are a part of linguistic culture and since language policy is often rooted in linguistic culture, attitudes cannot be ignored, (Schiffman, 1996).

As a multilingual society, Ghana uses English as the official language and so English occupies a prominent position in the language landscape of the country: Ghana has a long history of contact with English, and English is the only link language between speakers of different languages in the domains of government, higher education, entertainment, etc. Thus, advantages like prestige, functionality, and high status are associated with the use of English. This inequitable relationship between English and the local languages in Ghana is reported to be creating a situation where most Ghanaians, especially the youth, are developing negative attitudes towards their own languages (Ngula, 2011). This negative attitude is reinforced by parents who encourage their wards to speak only English, even at home. If this situation is the case, it has dire consequences for the maintenance and development 
of the local languages in Ghana. It is against this background that the researcher proposes to conduct an exploratory study to ascertain the attitude of Senior High School students in the New Juabeng Municipality towards English in relation to their mother tongues and to examine what accounts for students' language use in the various domains.

Research on language attitude, is very often based on two theoretical approaches: either the behaviourist approach or the mentalist approach, (Fishman and Agheyisi, 1970: and Fasold, 1984). According to the behaviourist view, attitudes are dependent variables which must be studied by observing users' responses to certain languages. That is, attitudes can be statistically determined by observing actual behaviour in social situations.

The mentalist view, on the other hand, posits that attitudes are a mental and neutral state of readiness which cannot be observed directly, but must be inferred from the subject's introspection. This work is non-experimental and is based on the mentalist model as the researcher aims to make inferences from the respondents' speech behaviour.

\subsection{Language Choice}

Most areas in several parts of the world are inhabited by diverse linguistic families and groups. This diversity of language within a given area or locality also means that a people's social and economic structures are also varied. Dorian (1981), states that the diversity of languages leads to the unavoidable concept of bilingualism among the local speakers. It is then expected that instances of partial and complete language shift shall occur and even diglossia may set in at some point in time. There is a well-documented tendency for some speech communities to change over time from ones first language to another (Gal, 1979). Fasold (1984) states that language use has been extensively studied in three disciplines namely sociology, social psychology and anthropology. From the perspective of a sociologist who is interested in searching for language use through the study of social structure, Fishman (1968) posits domain analysis. Under domain analysis, 'domains' are regarded as institutional contexts in which one language is more likely to be appropriate than another and are to be seen as constellations of other factors such as topic, location and participants.

Baker and Jones (1998) state that the concept of domain may include such notions as formality and informality. They also add that minority languages are linked with informal situations while majority languages are connected with formal situations like education or work. Although different studies employ different domains, common domains include home and family, neighborhood, schooling, mass media, business and commerce, and so on. Data concerning domains of language use are generally obtained through questionnaires and interviews and studied by means of statistical analysis (Fasold, 1984). In this vein, language use is critical to the understanding of the linguistic situation in a multilingual set up such as the New Juaben municipality where the majority of the population is multilingual. When people have command over two or more languages, they make choices as to when and where to use a certain language. The choices speakers make as to when to use what language rests on their attitude concerning the language of choice. As group patterns begin to emerge, implications about the roles of languages in a multilingual community can be translated into explanations about how that community operates in general.

A look at second cycle students in the New Juaben municipality clearly shows that they have deservedly managed to accord each domain its appropriate language choice. Twi has been accorded its position as the home language therefore its communicative role is clearly spelt out and its vitality is assured.

\subsection{Language and Identity}

Most works on language and identity are inspired in post-structuralism and adopts a social constructivist perspective according to which identity is about the multiple ways in which people position themselves and are positioned, that is, the different subjectivities and subject positions they inhabit or have ascribed to them, within particular social, historical and cultural contexts (Block, 2007a, 2007b, 2009; Duff, 2012; Norton, 2010; Norton \& Toohey, 2011). Duff (2012) explains post-structuralism as an approach to research that questions fixed categories or structures, oppositional binaries, closed systems, and stable truths and embraces seeming contradictions. Poststructural researchers examine how such categories are discursively and socially constructed, taken up, resisted (the sight of struggle), and so on. As Claire Kramsch notes, "the term subject position refers to the way in which the subject presents and represents itself discursively, psychologically, socially, and 
culturally through the use of symbolic systems" (Kramsch, 2009, p. 10).

While the background of most language and identity research can be found in poststructuralist thinking which is often linked to work in psychology (e.g., Weedon, 1997, 2004), researchers have tended to take a decidedly social view of identity, focusing in particular on how identity emerges in interactions as part of the day-to-day engagement in social activity, or "finding" identity in the narratives produced by individuals who have been asked to talk about this lives. However, as Layder notes in a critique of how identity had been framed in the Social sciences at the end of the 20th century, "it would be a mistake to think that the self is simply a social construct and that it has only an outer texture that is moulded and shaped by external social forces" (Layder, 1997, p. 48). Layder calls this approach to identity the "social constructionist fallacy", which he describes as "the tendency for sociologists to avoid examining the psychology of individuals for fear of producing explanations that are inappropriate or couched at the wrong level" (Layder, 1997, p. 51). As a way of avoiding the "social constructionist fallacy", Layder proposes an approach to identity that examines what he calls the individual's "psychobiography", that is, the "life career" which is the development of self, via activity and interaction, over time and space. This "life career" is composed of more institutionalized experiences, which are common to all individuals who engage in similar activities in similar settings, and more personalized experiences, which contribute to the construction of what Layder calls a "unique cluster of personality characteristics and typical behaviours" (Layder, 1997, p. 39). In this way, Layder attempts to move to a more psychological notion of identity as a complement to the more social one.

It has often been assumed that ethically different speakers are not able to handle the formal criteria for giving information or producing contextually relevant talk in situation with which they have little direct experience, such as job interview, public debates, or discussion. Much of the discussion has proceeded as if speaking appropriately required the learning of different script, and a different set of semantic and lexical options. The real problem is that whatever the situation, whether a formal interview or an informal meeting, the need in all communication for all people who are relative strangers to each other is to achieve a communicative flexibility, an ability to adapt strategies to the audience and to the signs, both direct and indirect, so that the participants are able to monitor and understand at least some of each other's meaning. Meaning in any face-to-face encounter is always negotiable; it is discovering the grounds for negotiation that requires the participants' skills. Many of the meaning and understandings, at the level of ongoing processes of interpretation of speaker's intent, depend upon culturally specific conventions, so that much of the meaning in any encounter is indirect and implicit. The ability to expose enough of the implicit meaning to make for a satisfactory encounter between strangers or culturally different speakers requires communicative flexibility.

Some initial insights into how we can study the achievement of communicative flexibility come from work on nonverbal communication. Through frameby-frame microanalysis of film it can be shown that communication depends upon usually unnoticed behavior cues and postures which have interactional, i.e., social, significance. Birdwhistell (1970) and Hall (1992b) have demonstrated that (1) taken-for-granted and subconsciously given nonverbal signs play an integral part in signaling of attitudes and intent in nonverbal communication, and (2) misunderstanding can arise in cross-cultural communication when the relevant signaling conventions differ. Considerable systematic analysis in this area has concentrated on isolating the actual physical behaviors that could potentially play a communicative role. A distinction was made between three basic kinds of signals; (1) micro signals, such as eye blinks or the contraction of facial muscles, which often go unnoticed, (2) proxemic signals such as gaze directions, posture, and body orientation, and (3) complexes of signs that carry meaning in and Friesen (1969). A second research approach has explored the coordination (Kendon, 1970). It has been demonstrated that all natural conversations are characterized by interspeaker coordination of signals. There is further evidence that nonverbal signs are rhythmically coordinated with verbal signs, both at the micro level of syllables and at the macro level of utterances (Condon and Ogesten 1969).

\section{Methodology}

There are three assessment techniques relevant to the study of language attitudes: content analysis of societal treatment, direct measurement and indirect measurement (Sebastian 1982: 7).

The direct measurement technique observes language attitudes by the use of questionnaires (either in written form or in individual interviews). 
Frequently asked questions concern language evaluation, language preference, desirability and reasons for learning a particular language, evaluation of social groups who use a particular variety, selfreports concerning language use, desirability of bilingualism and bilingual education, and opinions concerning shifting or maintaining language policies. The method tends to focus upon beliefs (ibid, 7)

The population for the study was made up of all students in second cycle institutions in the New Juabeng municipality. A sample size of ten (15) students from two second cycle institutions were accidentally selected for an in-depth interview using a ten point structured interview guide.

Next, a thirteen statement questionnaire was administered to 30 students from two Senior High Schools in the New Juabeng Municipality. First, in each school, a class was selected accidentally and then the simple random method was used to select the 30 students, 15 from each school, to respond to the questions.

The research instruments used in the study were the interview and questionnaire. The interview was used to seek information on students' language use in the various domains, and the reasons behind the use. The questionnaire was also used to determine students' patterns of language choice and use.

\section{Findings and Discussion}

Generally, attitudes toward a particular language can be arrived at from the respondents' patterns of language choice and use in the various domains and their intention of using the language in the different domains of use. In this section therefore, the researcher discusses students' use of language in the various domains and the reasons for that, and their pattern of language choice.

\subsection{Language Use in the Various Domains}

\subsubsection{Language use in the Family}

On the use of language in the family, three groups were identified.

The first group comprises students who use their L1 (first language or mother tongue) throughout at home. The reasons this group gives for this situation are that

- $\quad$ they feel most comfortable with it;

- that is what the parents speak at home (important to note the parent's influence in determining the language to be spoken at home);

- that the L1 is simply more expressive;

- $\quad$ that parents are illiterate.

The second group comprises those who reported using L1 with the parents, but use English with their siblings at home. Most of these students are actually encouraged to use English even though parents do not speak English themselves. The following are some of reasons given to explain this situation.

First, the students in this category explained that their parents are illiterate and therefore cannot speak English.

Next, they explain that their parents encourage them to speak English so that they will be to be more proficient in English.

Another reason they gave was that speaking English with siblings is a part of them and that they are brought up to use English. Sometimes too, the siblings cannot speak the L1 well, so in such a situation, the use of English is the only choice.

In fact the data here supports findings of AndohKumi (1999) that explains why some communities in Ghana support early English medium. Some of the reasons some parents include

- The purpose of schooling is to learn English

- English can take children to places

- When you go to school and at the end you do not understand English then it is useless

It is clear that most of these parents think of education in terms of one's ability to speak English. So for them literacy equals proficiency in English. This might explain why the parents of this category of Students insist that their children speak English at home, though they themselves are not proficient in English.

The next group is made up of respondents who use English throughout at home, because the parents encourage it. As one respondent says, 'with my Dad, it is a must we use English, especially when we are watching TV news'. This situation poses a great challenge as far as language loyalty is concerned. The point is that the attitude of some speakers of vernaculars is responsible for weakening of loyalty to the mother tongue in younger generations, (De Klerk, 1999). Also, as explained by Bamgbose (2003), a family that abandons its mother tongue in favour of 
English as a medium of communication in the home cannot at the same time complain that its mother tongue has been marginalized in other domains. Obviously these are parents who are proficient in English and who do not think the mother tongue has any educational or social value. In fact, such attitudes are partially responsible for the dominance of English and the lack of development and growth of local languages in most African countries.

\subsubsection{Language Use among Friends of the Same} Sex

In the domain of friendship, most of the students interviewed responded that they speak L1 to friends who speak their L1, but speak English to those who do not speak their L1, even though some of these friends share common local languages with the respondents. What this means is that if for example, student A is Ashanti and student B is Ewe, though student B may be proficient in Twi, he prefers to speak English with student A. This situation seems to suggest that these respondents prefer speaking English to speaking a second Ghanaian language to friends who do not share their L1.

It can thus be inferred that there is competition between the speakers of local languages in Ghana and this is one factor that has promoted the dominance of English. This situation is confirmed by the fact that when the respondents were asked about what language they use in talking to people they are meeting for the first time in a social gathering, and when introducing friends, almost every one of them said they use English. This is in spite of the fact that these respondents may share a second Ghanaian language with those they are interacting with.

The above situation is an example of what Baker (1992) defines as a "language conflict attitude": "the underlying assumption is of competition, one language threatening the other. Positive consequences for one language imply negative consequences for the other language. This gives the impression of languages existing in a kind of balance. As one language prospers, the other declines.

It must however be mentioned that the fact that two students whose mother tongues are mutually intelligible speak English does not necessarily mean that there is competition between their languages. It could be that in a multilingual country like Ghana, English is the link language among speakers of different language and this may be the underlying factor in the choice of language, Bamgbose (2003).

\subsubsection{Language Use among Students of the Opposite Sex}

In talking to the opposite sex, both in school and elsewhere, all the respondents indicated that they use English. This is irrespective of the fact that some members of the opposite sex the respondents talk to share either one or two Ghanaian languages with the respondents. Some respondents explained that they speak to the opposite sex to show that they (respondents) can speak English. Others maintain they speak English to show that they are educated. In fact, one male indicated that speaking to the opposite sex in English amounts to flexing (act of showing off) and another said, it shows courtesy.

First, these responses suggest that English occupies a higher status in the Ghanaian society compared to the other local languages. Thus, by speaking the English language, the students are just tapping into the wealth of prestige associated of the English language, and this is the kind of attitude that erases language loyalty.

Second, responses like 'I speak my L1 with my parents because they are illiterate', and 'I speak English with the opposite sex because I want to show that I am literate or educated', suggest that being able to speak English means one is educated and therefore, if a person does not speak English, he is not educated or he is illiterate.

\subsection{Discussion of Data from the Questionnaire}

Data from the questionnaire were used to complement those from the interview and so they bordered on the attitude of students towards English and their mother tongue.

First, questions one, three, five, six, ten and twelve (please see table below) examine the value students put on English language in Ghana. 
Frequency of responses to attitude statements $1-13$ (Total Sample of students $=30$ )

\begin{tabular}{|c|c|c|c|c|}
\hline & $\begin{array}{l}\text { Strongly } \\
\text { agree }\end{array}$ & Agree & Disagree & $\begin{array}{l}\text { Strongly } \\
\text { disagree }\end{array}$ \\
\hline \multirow[t]{2}{*}{ 1.ability to speak both L1 and English is an advantage } & 20 & 6 & 3 & 1 \\
\hline & $66.7 \%$ & $20.0 \%$ & $10.0 \%$ & $3.3 \%$ \\
\hline \multirow{2}{*}{\multicolumn{2}{|c|}{$\begin{array}{l}\text { 2.many Ghanaians like speaking English because it is the } \\
\text { most important language in Ghana }\end{array}$}} & 1 & 21 & 8 \\
\hline & & $3.3 \%$ & $70.0 \%$ & $26.7 \%$ \\
\hline \multirow[t]{2}{*}{ 3.the ability to speak English is an advantage } & 20 & 10 & & \\
\hline & $66.7 \%$ & $33.3 \%$ & & \\
\hline \multirow[t]{2}{*}{ 4.if you always use L1 in school, you are branded 'local' } & 7 & 19 & 4 & \\
\hline & $23.3 \%$ & $63.3 \%$ & $13.3 \%$ & \\
\hline \multirow[t]{2}{*}{ 5.English offers good job opportunities } & 20 & 10 & & \\
\hline & $66.7 \%$ & $33.3 \%$ & & \\
\hline \multirow{2}{*}{$\begin{array}{l}\text { 6.to be admitted to a public post, one should be able to } \\
\text { speak English }\end{array}$} & 7 & 23 & & \\
\hline & $23.3 \%$ & $76.7 \%$ & & \\
\hline \multirow[t]{2}{*}{ 7.most students do not want to learn their L1 at school } & 9 & 21 & & \\
\hline & $30.0 \%$ & $70.0 \%$ & & \\
\hline \multirow[t]{2}{*}{ 8.the status of English is higher than my L1 in Ghana } & & 3 & 15 & 12 \\
\hline & & $10.0 \%$ & $50.0 \%$ & $40.0 \%$ \\
\hline \multirow[t]{2}{*}{ 9.people should be proud to speak their L1 anywhere } & 21 & 6 & 3 & \\
\hline & $70.0 \%$ & $20.0 \%$ & $10.0 \%$ & \\
\hline \multirow[t]{2}{*}{ 10.without knowledge in English, I cannot get a job } & 11 & 15 & 4 & \\
\hline & $36.7 \%$ & $50.0 \%$ & $13.3 \%$ & \\
\hline \multirow{2}{*}{$\begin{array}{l}\text { 11.it does not matter if you do not have command over } \\
\text { the English language in Ghana }\end{array}$} & & 1 & 7 & 22 \\
\hline & & $3.3 \%$ & $23.3 \%$ & $73.3 \%$ \\
\hline \multirow[t]{2}{*}{ 12.without knowledge of my L1, I cannot get a job } & & & 9 & 21 \\
\hline & & & $30.0 \%$ & $70.0 \%$ \\
\hline \multirow[t]{2}{*}{ 13.many people are shy to speak their L1 in public } & 10 & 17 & 3 & \\
\hline & $33.3 \%$ & $56.7 \%$ & $10.0 \%$ & \\
\hline
\end{tabular}

In question one, the researcher wanted the students' opinion on whether proficiency in both the mother tongue and English is an advantage in Ghana. Though 26 out of the 30 students agreed that it is advantageous to be proficient in both languages, four of them disagreed.

However, in question three, where they were asked about whether it is advantageous to learn English, the four students who disagreed in question one now agreed. The implication is that four respondents do not value their mother tongue.

On questions one, six and ten, all thirty respondents agreed that to stand a chance of getting a job, to get a job and to be admitted to a public post, English is necessary. This supports the findings of Bamgbose (2003) that because of prospects of better jobs and upward social mobility that English confers, people deliberately demand and opt for it, especially, where it is used as an official language.
Questions four, seven and thirteen were meant to obtain information on students' attitude towards their mother tongue. The results show that students place very little value on their mother tongue. For question four, twenty-six out of the thirty students think they will be branded local if they speak their mother tongue. For question seven, all thirty students agree that most students do not want to learn their mother tongue in school. To question thirteen, twenty-seven of the thirty students think many students are shy to speak their mother tongue in public. The data indicate that majority of the students are not prepared to speak or learn their mother tongue and this has serious implication for the development and maintenance of the local languages in Ghana.

However, an overwhelming majority disagree that English is spoken because it is the most important language in Ghana or English is higher than their mother tongues. Though it is true that 
some of the students learn English because of the advantages and prestige associated with it, nationalism does not feature as a justification for promoting English, (Bamgbose, 2003).

One fact that can be deduced from the study is that there is a wealth of prestige associated with the English language that most of the respondents through their responses are trying to tap into. As explained by Saah (1986), English language has great prestige in Ghana and that competence in English is a gateway to advancement in society. It is a requirement to be considered a literate, to get employment, etc.

\section{Conclusions}

It is clear from the data that most students associate English with prestige and therefore have a very positive attitude towards English. It can also be concluded that generally, the students have a poor attitude towards the local languages. Furthermore, most of the students and their parents erroneously equated literacy to proficiency in the English language. Again, the main reason for the positive attitude towards English is the huge opportunity that English offers.

Overall, the data reflect a very poor attitude towards local languages in Ghana. English is perceived as the only language worth being literate in or even the sole language worth investing in - both in financial and in cognitive terms - since early childhood, to the detriment of local languages. This situation may explain why the present early exit language policy in Ghana has failed to a large extent.

Lastly, the poor attitude towards the local languages is due to the fact that the local languages do not seem to offer any practical or social worth, in the opinion of the respondents. There is therefore the need for further studies to determine the local languages in Ghana to attract the youth so as to ensure that the local languages do not become extinct.

\section{References}

Agheyisi, R. and Fishman, J. (1970) Language Attitudes: A Brief Survey of Methodological Approaches. An Anthropological Linguistics, 12. Pp. 137-157.
Bamgbose, A. (2003). A Recurring Decimal: English in Language Policy and Planning. World Englishes. 22 (4). Pp. 419-431.

Baker, C. (1988). Key Issues in Bilingualism and Bilingual Education. Clevedon: Bilingual Matters.

Birdwhistell, R. L. (1970). Kinesics in Context: Essays on Body Motion Communication. Philadelphia: University of Pennsylvania Press.

Block, D. (2007a). Second Language Identities. London: Continuum.

Block, D. (2007b). The Rise of Identity in SLA Research, Post Firth and Wagner (1997). Modern Language Journal, 91, 861-874. http://dx.doi.org/10.1111/j.15404781.2007.00674.x

Block, D. (2009). Identity in Applied Linguistics: The Need for Conceptual Exploration. In Li Wei \& V. Cook (Eds.), Contemporary Applied Linguistics, Volume 1 (pp. 215-232). London: Continuum.

Crystal, D. (1992). An Encyclopedic Dictionary of Languages. Cambridge, MA: Blackwell.

De Klerk, V. (1999) 'Black South African English: Where to from here?' World Englishes 8 (3).

Duff, P. (2012). Issues of Identity. In S. Gass \& A. Mackey (Eds.), The Routledge Handbook of Second Language Acquisition (pp. 410-426). London: Routledge.

Fasold, R. (1984). The Sociolinguistics of Society. Oxford: Basil Blackwell.

Friesen, W.V. (1974). Nonverbal Behaviour and Psychopathology. The Psychology of Depression: Contemporary Theory and Research. (ed. R. J. Friedman and M. N. Katz), pp 203-32. J. Winston, Washington D. C.

Hall, S. (1992b). New Ethnicities. In J. Donald \& A. Rattansi (eds.), "Race", Culture and Difference (pp. 252-259). London: Sage.

Hamers, J. and Blanc, M. (1989). Bilinguality and Bilingualism. Cambridge: Cambridge University Press.

Kendon, A. (1970). Movement coordination in social interaction: Some examples described. Acta Psychologica 32: 101-125.

Kramsch, C. (2009). The Multilingual Subject. Oxford: Oxford University.

Layder, D. (1997). Modern social theory. London: UCL Press.

Ngula, R.S. (2011) 'Ghanaian English: Spelling Pronunciation in Focus', Language in India, Vol. 11, No.2, pp. 22-23 
Norton, B. (2010). Language and identity. In N. Hornberger \& S. McKay (Eds.), Sociolinguistics and Language Education (pp. 349-369). Bristol, UK: Multilingual Matters.

Norton, B., \& Toohey, K. (2011). Identity, Language Learning, and Social Change. Language Teaching,44,412446.http://dx.doi.org/10.1017/ S0261444811000309
Saah, K. (1986). 'Language Use and Language Attitudes in Ghana'. Anthropological Linguistics, 28. Cambridge, MA: Blackwell.

Weedon, C. (1997). Feminist Practice and Poststructuralist Theory. Oxford 